\title{
lodinated Polyethylene Glycol-based Hydrogel Tissue Marker
}

National Cancer Institute

\section{Source}

National Cancer Institute. Iodinated Polyethylene Glycol-based Hydrogel Tissue Marker.

NCl Thesaurus. Code C133359.

A radiopaque hydrogel containing cross-linked, iodinated polyethylene glycol (PEG) particles in a viscous carrier, with potential use as a contrast agent to enhance marking of soft tissue during a surgical procedure and concomitant radiotherapy upon computed tomography (CT), magnetic resonance (MR) and ultrasound imaging. Upon intratumoral injection, iodinated PEG-based hydrogel tissue marker localizes to and is maintained in soft tissue. Upon MR, ultrasound and/or CT imaging, the visualization of the tumor tissue is enhanced, which can facilitate tumor removal and image-guided radiotherapeutic treatment. The hydrogel particles are stable and visible through 3 months, after which they liquefy, and are absorbed by the body and cleared in the urine. 